\title{
Prevalence, incidence and predictive factors for hand eczema in young adults - a follow-up study
}

Arne Johannisson ${ }^{1 *}$, Ann Pontén ${ }^{2,3}$ and Åke Svensson ${ }^{4,5}$

\begin{abstract}
Background: Hand eczema is common in the general population and affects women twice as often as men. It is also the most frequent occupational skin disease. The economic consequences are considerable for society and for the affected individuals.

Methods: To investigate the prevalence and incidence of hand eczema and to evaluate risk factors for development of hand eczema in young adults. Subjects and methods; This is a prospective follow-up study of 2,403 young adults, 16 - 19 years old in 1995 and aged 29 - 32 years, 13 years later, in 2008. They completed a postal questionnaire that included questions regarding one-year prevalence of hand eczema, childhood eczema, asthma, rhino-conjunctivitis and factors considered to affect hand eczema such as hand-washing, washing and cleaning, cooking, taking care of small children and usage of moisturisers. These factors were evaluated with the multinominal logistic regression analysis.

Results: The one-year prevalence of hand eczema was 15.8\% (females 20.3\% and males 10.0\%, p < 0.001). The incidence was 11.6 cases per 1000 person-years (females 14.3 and males 5.2, p<0.001). Childhood eczema was the most important risk factor for hand eczema. The odds ratios were 13.17 when having hand eczema 1995 and 2008 compared to 5.17 in $2008(p<0.001)$. A high frequency of hand washing was important in predicting hand eczema only when having 1-year prevalence 2008, OR $1.02(p=0.038)$.
\end{abstract}

Conclusions: After 13 years an increased 1-year prevalence of hand eczema was found. The significant risk factors for hand eczema changed over time from endogenous to exogenous factors.

Keywords: Hand eczema, Childhood eczema, Prevalence, Incidence, Cohort, Gender, Skin care, Hand-wash

\section{Background}

Hand eczema is common in the general population. In a recent review of studies in the general population from mostly European countries, the 1-year prevalence rates ranged from $6.5 \%$ to $17.5 \%$ [1]. Hand eczema is $1.5-2$ times more common in females compared with males $[2,3]$. Swedish estimates of 1 -year prevalence of hand eczema in different age-groups have varied from $6.5 \%$ to $11.8 \%$ [4-6]. Among Swedish 20-29 year-olds, the 1year prevalence of hand eczema was reported to range from $7.5 \%$ to $10.8 \%[3,4]$. Furthermore, hand eczema is the most common occupational skin disease [7].

Occupation-related hand eczema has many negative consequences. The economic costs are considerable for

\footnotetext{
* Correspondence: arne.johannisson@med.lu.se

'Department of Health Sciences, Lund University, Box 157, 22100 Lund, Sweden

Full list of author information is available at the end of the article
}

affected individuals and for society [8,9]. Hand eczema has been shown to have an unfavourable long-term prognosis [10] and to impair quality of life [11]. These consequences could be reduced by identifying and preventing risk factors.

Several exogenous risk factors for hand eczema have been reported: occupational exposure, use of detergents and wet work at home [4,12-14]. The identification and evaluation of risk factors for the development and persistence of hand eczema are important especially among young adults. During this period of life, type of occupation, household work and childcare are factors that are important to study because they might be related to the development of hand eczema. Taken together, these circumstances justify follow-up studies in early adulthood.

The aim of the present study was to investigate the prevalence and cumulative incidence of hand eczema

\section{Biomed Central}

(c) 2013 Johannisson et al.; licensee BioMed Central Ltd. This is an open access article distributed under the terms of the Creative Commons Attribution License (http://creativecommons.org/licenses/by/2.0), which permits unrestricted use, distribution, and reproduction in any medium, provided the original work is properly cited. 
and to evaluate factors that can influence the development and recurrence of hand eczema in young adults.

\section{Methods}

\section{Study group}

This is the 13 year prospective follow-up study of a cohort of pupils in upper secondary school, 16-19 years old at the baseline assessment, and consequently they were 29-32 years old at follow-up. In 1995, 2,572 pupils in the four secondary schools in Växjö completed a selfadministrated questionnaire regarding hand eczema, the response rate was $98.6 \%$. Växjö is a town in southern Sweden with approximately 70,000 inhabitants $[15,16]$. In 1995, 74\% of 16 - 19 years-olds attended secondary school in the study area, which was consistent with the overall attendance rate in Sweden. The 13-year follow-up of this cohort was performed in 2008. At both occasions the questionnaire was mailed in springtime. Swedish personal identification numbers were used to get updated addresses from the Swedish Population Address Register (SPAR). Addresses were found for 2,403 of the original 2,572 participants (Figure 1); 169 were unreachable: 106 had personal identification numbers not matching the SPAR register, 35 had emigrated, 21 had moved without providing a forwarding address, five were deceased, and two were not traceable for reasons of secrecy.

\section{Questionnaire}

In 1995 the questionnaire was based on the Toulihampi questionnaire [17]. The questionnaire in 2008 was based on the Nordic Occupational Skin Questionnaire 2002 (NOSQ-2002), [18]. The questions regarding hand eczema were almost the same in the two questionnaires and the answer alternatives were exactly the same. Some additional questions constructed by the investigators were included in the 2008 questionnaire (See Additional file 1).
Topics surveyed by the questionnaire were: hand eczema, childhood eczema, asthma and rhino-conjunctivitis, household size and family structure, occupation and everyday activities, hand washing and skin care.

\section{Distribution of the questionnaire}

A self-administrated postal questionnaire and a pre-paid return envelope were distributed in late May 2008. A postcard was sent at the beginning of June as a first reminder. At the end of August, a second reminder was sent which included a copy of the questionnaire, a pencil and a prepaid return envelope. Finally, a postcard was sent in the middle of September as a third and final reminder.

\section{Data analysis and statistics}

One-year prevalence of hand eczema was estimated from reported hand eczema at present or having had hand eczema some time during the last 12 months (See Additional file 1). The question regarding the 1-year prevalence was previously validated $[19,20]$. The question on point prevalence was validated, and sensitivity $(73 \%)$ and specificity (99\%) were calculated [15]. To estimate the true 1-year prevalence for this cohort, a calculation of the 1-year prevalence in relation to sensitivity and specificity was made by using the formula: $\mathrm{P}=\left(\mathrm{P}^{*}+\right.$ $($ specificity-1) $) /($ sensitivity $+($ specificity -1$))$. $\mathrm{P}$ is the estimated true 1-year prevalence in the population and $\mathrm{P}^{*}$ is the 1-year prevalence in the sample $[5,15,21]$.

The cumulative incidence was calculated on the individuals reporting having 1-year prevalence or ever having had hand eczema 2008 minus those who had 1-year prevalence or ever had had hand eczema in 1995. The cumulative incidence is presented as the percentage of new cases of hand eczema in the cohort. Incidence rate is presented as new cases per 1000 person-years, i. e. the cumulative incidence/13 years $\times 1000$.

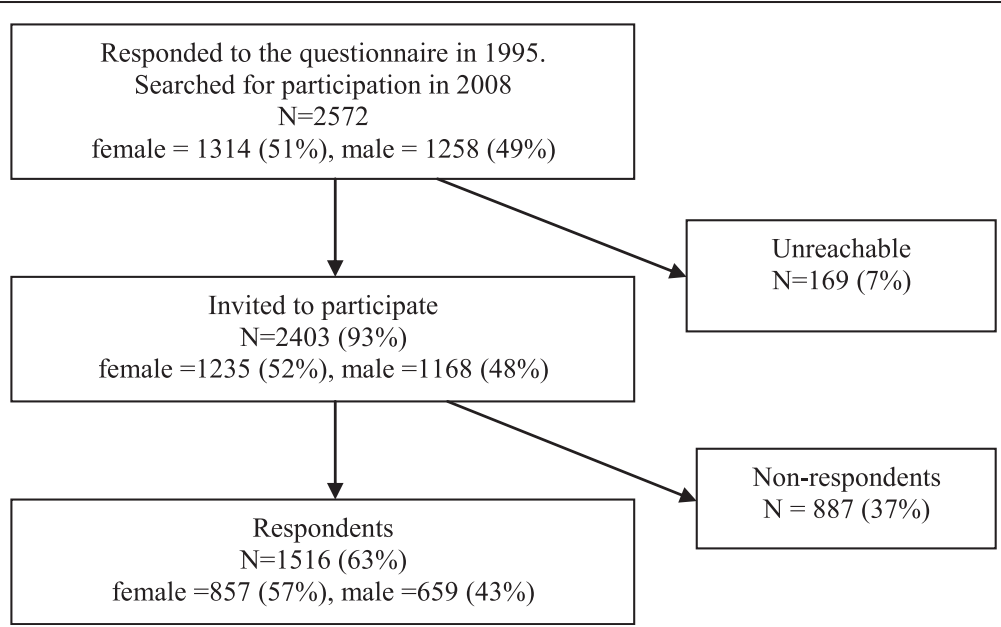

Figure 1 The flow-chart of the cohort. 
Four groups were constructed with the intention to analyse risk factors and the development of hand eczema over time. The groups were constructed as follows: those who reported having a 1-year-prevalence in 1995 and in 2008 are in group HX9508, those who reported having a 1-year-prevalence in 1995 but not in 2008 are in group HX95, those who reported having a 1-year-prevalence in 2008 but not in 1995 are in group HX08, and those who reported that they never had hand eczema are in group NoHX.

The reliability over time of self-reported childhood eczema in 1995 and then reporting the same in 2008 was determined by calculating positive predictive value (PPV); i.e. the percentage positive agreement in 2008 among the yes-respondents from 1995. The negative predictive value (NPV); i.e. the agreement of no-answers in 1995 and 2008 was also calculated.

Potential exogenous risk factors for developing hand eczema such as household size, time required for household work, frequency of hand washing, skin protective habits, working hours outside home and leisure activities were investigated by dividing the cohort into two groups. The respondents who had 1-year prevalence of hand eczema 2008, i.e. the merged groups HX9508 and HX08, denominated the HX group, and the group that reported never having had hand eczema, the NoHX group. Furthermore, hand eczema was also studied in the two hand eczema groups separately regarding these factors.

Regarding occupation, the respondents were asked not only to tell their profession, but also to give information about work tasks.

The groups HX9508, HX95 and HX08 were compared to the group NoHX using a multinominal logistic regression model. The endogenous factors childhood eczema, asthma and rhino-conjunctivitis as reported in 2008 were used. The response choices in this calculation were Yes/No. Exogenous factors such as hand-washing (times a day), usage of moisturisers (dichotomised Daily/ Some time each week, some time each month, never), cooking, cleaning/washing laundry, and taking care of children 0-4 years of age (hours a day) were investigated.

Categorical data were presented as numbers and/or proportions in groups; quantitative data were presented by mean, median and quartiles. Nominal data were tested with the Chi-squared test. When the number of expected values was insufficient, Fisher's exact test was used. When comparing groups over time, McNemar's test was used. Ordinal and interval data were tested with Kruskal-Wallis $\mathrm{H}$ test and Mann-Whitney U-test in independent group comparisons. In the multinominal logistic regression analysis odds-ratios, 95\% confidence intervals and p-values were given for all the covariates. If data was missing for any covariate, the individual was not included in the analysis. A p-value $<0.05$ was considered significant in all calculations. All statistical analyses were performed with SPSS 20.0 for Windows.

\section{Ethics}

The study was approved by the The Regional Ethical Review Board in Lund, (application no 156/2008).

\section{Results}

The flow-chart of the cohort is shown in Figure 1. Out of the 2,403 participants from the original cohort who received a questionnaire in the mail, 1,516 responded to the questionnaire, which was a response rate of $63 \%$; $56 \%$ of the respondents were females. Significantly more females than males answered the questionnaire, $69.4 \%$ of the reachable original female cohort and $56.4 \%$ of the males $(p<0.001)$. However, in 2008 there were no significant differences between the respondents and nonrespondents in reporting 1-year prevalence of hand eczema in 1995 ( $\mathrm{p}=0.677)$. No significant differences were found within the genders in reported hand eczema in 1995 (females, $\mathrm{p}=0.490$; males, $\mathrm{p}=0.297$ ).

In the first dispatch, 899 (37\%) responded, the first postcard reminder yielded $158(10 \%)$ responses. On the second reminder 437 (32\%) responded. With the final postcard reminder, 22 (2\%) responded, which left 887 non-respondents.

\section{One-year prevalence of hand eczema}

The 1-year prevalence of hand eczema in 2008 was 15.8\%, Figure 2; females reported hand eczema twice as often as males, $20.3 \%$ versus $10.0 \%$, $(\mathrm{p}<0.001)$. The estimated true 1 -year prevalence for this cohort was: $(0.158+(0.99-1)) /$ $(0.73+(0.99-1))=20.6 \%, 26.8 \%$ for females and $12.5 \%$ for males.The 1516 participants were allocated to any of the four groups as previously defined; HX9508 (83/1516, 5.5\%, 7.2\% females and 3.2\% males), HX95 (71/1516, 4.7\%; $5.6 \%$ females and 3.5\% males), HX08 (157/1516, 10.4\%; $13.1 \%$ females and 6.8\% males) and NoHX (1016/1516, $67.0 \% ; 61.4 \%$ females and $74.4 \%$ males). One hundred and sixty respondents (10.6\%) reported that they had had hand eczema at some time, but not in 1995 nor in 2008, 29 individuals, $1.9 \%$, did not answer the question. The higher proportion of females compared with males in the hand eczema groups compared with the NoHX group was significant $(\mathrm{p}<0.001)$.

\section{Incidence of hand eczema}

In 1995 in total 13.3\% (202/1516) reported they had or had had hand eczema, 139 females, (16.2\%) and 63 males (9.6\%), p<0.001. In 2008 an additional 198 individuals reported themselves having or having had hand eczema. Thus the cumulative incidence over the 13 years was $15.1 \%(198 / 1314)$, for the females $18.6 \%$ and for the males $10.7 \%, \mathrm{p}<0.001$. The incidence rate was estimated 


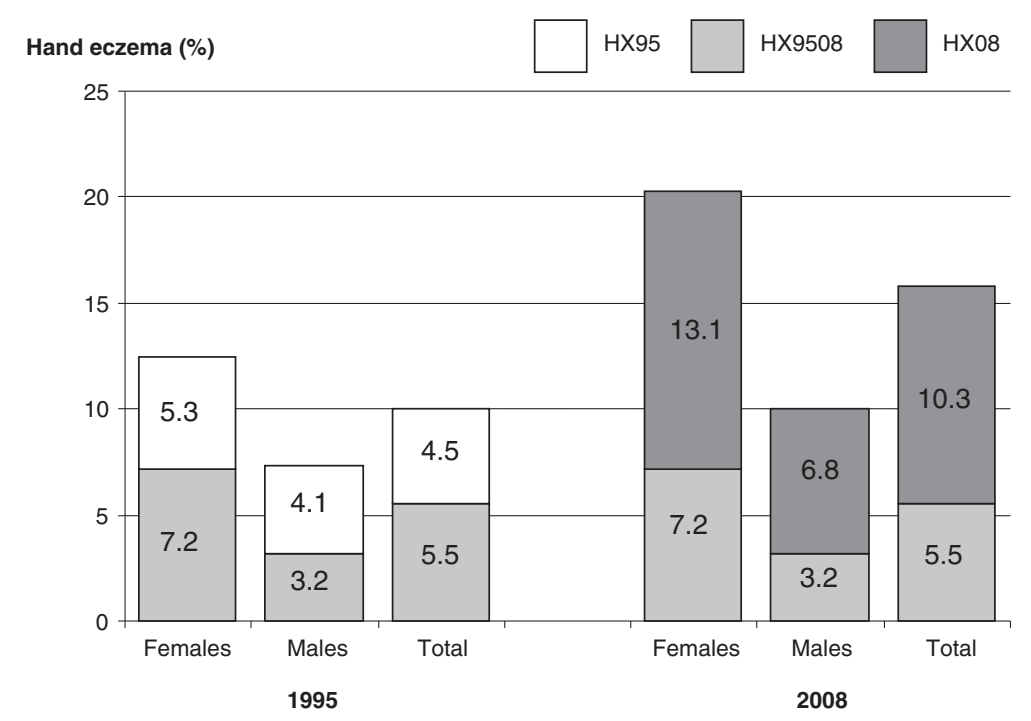

Figure 2 The proportions reporting hand eczema in 1995 but not 2008 (HX95), both 1995 and 2008 (HX9508), and only 2008 (HX08).

as 11.6 cases per 1000 person-years, 14.3 for females and 5.2 for males $(\mathrm{p}<0.001)$.

\section{Hand eczema versus childhood eczema, asthma, rhino-conjunctivitis and gender}

Childhood eczema was reported by 400/1516 (26.4\%) of the participants. The proportions of having had childhood eczema, asthma and rhino-conjunctivitis in the four groups in total and by gender for 2008 are shown in Table 1 . The proportions of the individuals reporting only childhood eczema; i.e. not in combination with asthma and/or rhino-conjunctivitis (146/1516, 9.6\%), were found to be: HX9508, 73.9\%; HX95, 41.7\%, HX08, 45.5\% and NoHX, $17.3 \%$ ( $\mathrm{p}<0.001)$. Only having had asthma was reported by $22 / 1516$ (1.5\%); within the groups: $1,1,0$ and 20 individuals respectively, $(\mathrm{p}=0.366)$. Only having had rhino-conjunctivitis was reported by $201 / 1516$ (13.3\%). Within the groups 4, 7, 11 and 179 individuals, respectively $(p=0.124)$.

\section{Self-reported childhood eczema in 2008 compared to 1995}

The question about childhood eczema was answered by 1323 of the 1516 respondents (87.3\%) in 2008. In 1995, 297/1323 individuals (22.4\%) reported childhood eczema, and 239 of these gave the same answer in 2008. This gives the positive predictive value (PPV) of $80.5 \%(239 / 297)$. The negative predictive value (NPV), i.e. reporting not having had childhood eczema in 1995 as well as in 2008, was $76.7 \%$ (610/795). When comparing genders, the PPV for females was $82.3 \%$ and the NPV was $77.0 \%$. The PPV for males was $75.6 \%$ and the NPV was $76.5 \%$. There were significant differences within three of the four groups between PPV and NPV; HX9508 group: PPV $=90.6 \%$ and $\mathrm{NPV}=35.0 \% \quad(\mathrm{p}=0.016) ; \mathrm{HX} 95$ group: $\mathrm{PPV}=76.7 \%$ and NPV $=60.7 \%(\mathrm{p}=0.611)$; HX08 group: $\mathrm{PPV}=94.0 \%$ and $\mathrm{NPV}=55.3 \% \quad(\mathrm{p}<0.001) ; \mathrm{NoHX}$ group: $\mathrm{PPV}=73.8 \%$ and $\mathrm{NPV}=77.6 \%(\mathrm{p}<0.001)$.

\section{Hand eczema and exogenous factors}

The results regarding potential exogenous risk factors for developing hand eczema are shown in Table 2. The individuals in the $\mathrm{HX}$ group reported a significantly higher frequency of hand washing compared to the NoHX group, mean 15.4 versus 11.7 times per day $(\mathrm{p}<$ 0.001). The females in the HX group had a significantly higher number of daily hand washing compared to the females in the NoHX-group, 17.4 versus 14.5 times per day $(\mathrm{p}<0.001)$.

Concerning skin care, daily use of moisturisers was reported by $60.5 \%$ in the HX group (females $67.6 \%$ males $41.5 \%$ ), and by $30.6 \%$ in the NoHX group (females $47.4 \%$ and males $12.7 \%$ ). The differences were significant between the two groups and between the genders within the groups $(p<0.001)$. Regardless of hand eczema, females used moisturisers significantly more often than males; $52.9 \%$ female versus $16.2 \%$ male daily users $(p<0.001)$, However, having hand eczema raised the reported usage of moisturizers by a factor 1.4 for females and 3.3 for males.

The exogenous factors were analysed between all four groups, in total as well as between genders (HX9508, HX95, HX08 and NoHX) and within genders in all groups, Table 3 . In total as well as within females, the HX08 group had a significantly higher frequency of hand washing at home and at work than the NoHX group $(\mathrm{p}<0.001)$. Regarding time spent at ordinary work; the HX08 group worked significantly less than the NoHX group $(\mathrm{p}=0.001)$. The HX08 group spent significantly more time cooking, cleaning and doing laundry than the 
Table 1 Prevalence of self-reported childhood eczema and/or asthma and/or rhino-conjunctivitis in 2008 with respect to 1-year prevalence of hand eczema and gender in the groups HX9508 (1-year prevalence of hand eczema 1995 and 2008), HX95 (1-year prevalence of hand eczema only 1995), HX08 (1-year prevalence of hand eczema only 2008) and NoHX (never having had hand eczema)

\begin{tabular}{|c|c|c|c|c|c|c|c|c|c|c|c|c|}
\hline \multirow{2}{*}{$\begin{array}{l}\text { The } 2008 \text { questionnaire } \\
\text { "Did you have eczema in your } \\
\text { childhood?" ( } n=1325,100 \% \text { ) }\end{array}$} & \multicolumn{3}{|c|}{ Group HX9508 } & \multicolumn{3}{|c|}{ Group HX95 } & \multicolumn{3}{|c|}{ Group HX08 } & \multicolumn{3}{|c|}{ Group NoHX } \\
\hline & $\begin{array}{c}\text { Females } \\
\text { n (\%) }\end{array}$ & $\begin{array}{l}\text { Males } \\
\text { n (\%) }\end{array}$ & $\begin{array}{l}\text { Total } \\
\text { n (\%) }\end{array}$ & $\begin{array}{c}\text { Females } \\
\text { n (\%) }\end{array}$ & $\begin{array}{l}\text { Males } \\
\mathrm{n}(\%)\end{array}$ & $\begin{array}{l}\text { Total } \\
\text { n (\%) }\end{array}$ & $\begin{array}{c}\text { Females } \\
\text { n (\%) }\end{array}$ & $\begin{array}{l}\text { Males } \\
\text { n (\%) }\end{array}$ & $\begin{array}{l}\text { Total } \\
\text { n (\%) }\end{array}$ & $\begin{array}{c}\text { Females } \\
\text { n (\%) }\end{array}$ & $\begin{array}{l}\text { Males } \\
\text { n (\%) }\end{array}$ & $\begin{array}{l}\text { Total } \\
\text { n (\%) }\end{array}$ \\
\hline "No" (n= 792, 59.8\%) & $10(16.1)$ & $3(14.3)$ & $13(15.7)$ & 19 (39.6) & $6(27.3)$ & $25(35.7)$ & $38(33.9)$ & $14(31.1)$ & $52(33.1)$ & $349(66.5)$ & $353(72.0)$ & $702(69.2)$ \\
\hline "Yes" $(n=400,30.2 \%)$ & $48(77.4)$ a> & $15(71.4)$ a> & $63(75.9) \mathbf{b}>$ & $22(45.8)$ a> & $14(63.6) a>$ & $36(51.4) \mathbf{b}>$ & $63(56.3) a>$ & $23(51.1) a>$ & $86(54.8)$ b> & $140(26.7) a<, c>$ & 75 (15.3) $\mathbf{a}<$ & $215(21.2) \mathbf{b}<$ \\
\hline "I do not know" ( $n=133,10.0 \%)$ & $4(6.5)$ & $3(14.3)$ & $7(8.4)$ & $7(14.6)$ & $2(9.1)$ & $9(12.9)$ & $11(9.8)$ & $8(17.8)$ & $19(12.1)$ & $36(6.9)$ & $62(12.7)$ & $98(6.6)$ \\
\hline
\end{tabular}

\section{"Have you ever had asthma?"}

$(n=1326)$

\begin{tabular}{lcccccccccccc}
\hline "No" $(\mathrm{n}=1082,81.6 \%)$ & $37(59.7)$ & $15(71.4)$ & $52(62.7)$ & $38(79.2)$ & $19(86.4)$ & $57(81.4)$ & $84(75.0)$ & $35(77.8)$ & $119(75.8)$ & $433(82.3)$ & $421(85.9)$ & $854(84.0)$ \\
\hline "Yes" $(n=217,16.4 \%)$ & $23(37.1)$ & $6(28.6)$ & $29(34.9) \mathbf{b}>$ & $8(16.7)$ & $2(9.1)$ & $10(14.3) \mathbf{b}<$ & $23(20.5)$ & $10(22.2)$ & $33(21.0) \mathbf{b}>$ & $84(16.0)$ & $61(12.4)$ & $145(14.3) \mathbf{b}<$ \\
\hline "I do not know" $(n=27,2.0 \%)$ & $2(3.2)$ & 0 & $2(2.4)$ & $2(4.2)$ & $1(4.5)$ & $3(4.3)$ & $5(4.5)$ & 0 & $5(3.2)$ & $9(1.7)$ & $8(1.6)$ & $17(1.7)$ \\
\hline
\end{tabular}

\section{"Have you ever had allergic}

symptoms from your nose

or eyes?" $(\mathbf{n}=1306)$

\begin{tabular}{lcccccccccccccccc}
\hline "No" $(\mathrm{n}=664,50.8 \%)$ & $20(32.3)$ & $5(25.0)$ & $25(30.5)$ & $26(54.2)$ & $11(52.4)$ & $37(53.6)$ & $41(36.9)$ & $16(36.4)$ & $57(36.3)$ & $280(54.2)$ & $265(54.9)$ & $545(54.5)$ \\
\hline "Yes" ( $n=582,44.6 \%)$ & $40(64.5) \mathbf{a}>$ & $15(75.0) \mathbf{a}>$ & $55(67.1) \mathbf{b}>$ & $21(43.8) \mathbf{a}<$ & $10(47.6) \mathbf{a}<$ & $31(44.9) \mathbf{b}<$ & $63(56.8) \mathbf{a}<$ & $24(54.5) \mathbf{a}<$ & $87(55.4) \mathbf{b}>$ & $211(40.8) \mathbf{a}<$ & $198(41.0) \mathbf{a}<$ & $409(40.9) \mathbf{b}<$ \\
\hline "I do not know" (n=60, 4.6\%) & $2(3.2)$ & 0 & $2(2.4)$ & $1(2.1)$ & 0 & $1(1.5)$ & $7(6.3)$ & $4(9.1)$ & $13(8.3)$ & $26(5.0)$ & $20(4.1)$ & $46(4.6)$ \\
\hline
\end{tabular}

Significant differences $(p<0.05)$ between groups, totals and/or genders are marked with bold letters. a: significant differences within females or within males in different groups, b: significant difference between totals, c: significant difference between females and males in a group, $<$ or $>$ : the group or the gender has significantly lower or significantly higher frequency than the compared group. Chi-squared test. 
Table 2 Comparisons of exogenous factors between the group with a 1-year prevalence of hand eczema in 2008 (Group HX), and the group reporting never having had hand eczema (Group NoHX)

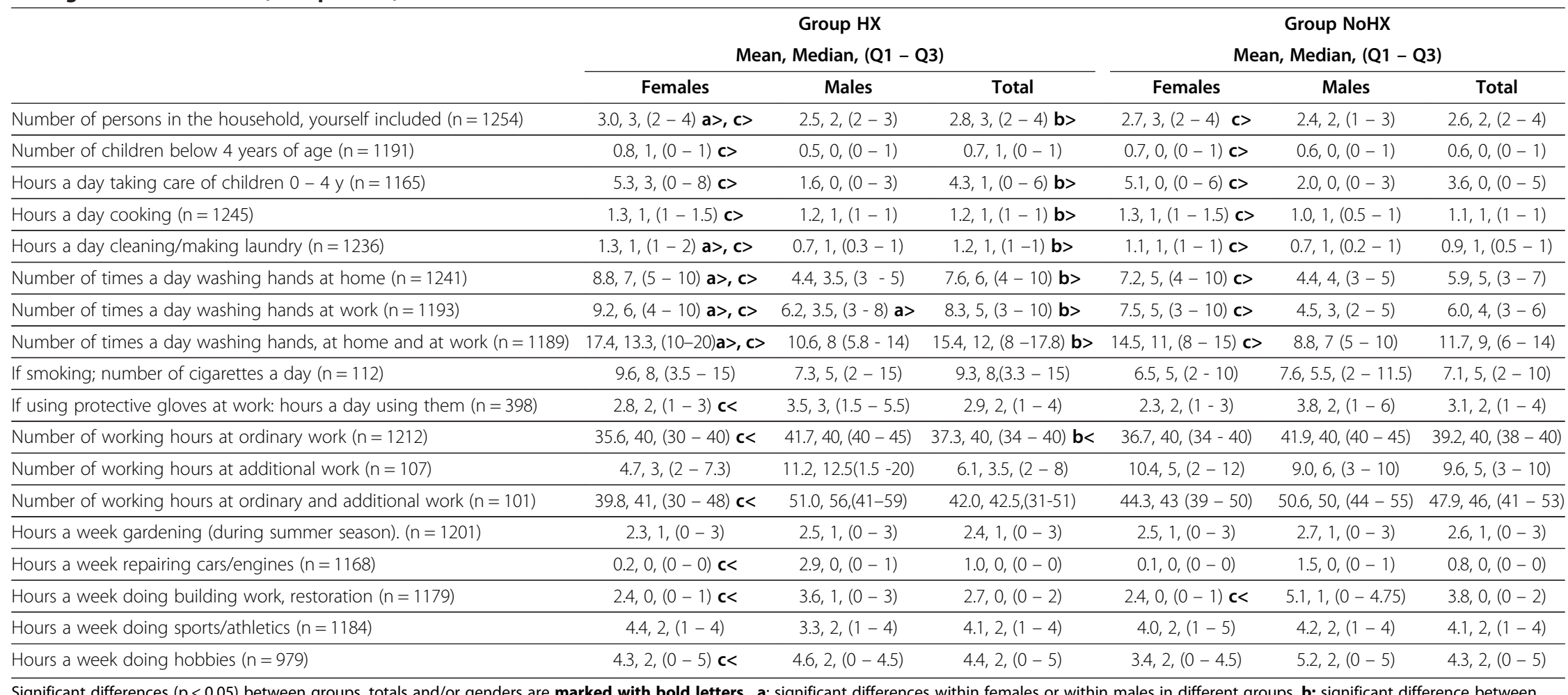

Significant differences $(p<0.05)$ between groups, totals and/or genders are marked with bold letters. a: significant differences within females or within males in different groups, b: significant difference between totals, $\mathbf{c}$ : significant difference between females and males in a group, < or >: the group or the gender has significantly lower or significantly higher frequency than the compared group. Mann-Whitney $\mathrm{U}$ test. 
Table 3 Comparisons of exogenous factors between the group HX9508, i.e. having had 1-year prevalence of hand eczema 1995 and 2008, the group HX95, i. e. having had hand eczema only 1995, the group HX08, i.e. having eczema only 2008 and the group NoHX, i. e. the group reporting never having had hand eczema

\begin{tabular}{|c|c|c|c|c|c|c|c|c|c|c|c|c|}
\hline & \multicolumn{3}{|c|}{$\begin{array}{c}\text { HX9508 } \\
\text { Mean (Q1-Q3) }\end{array}$} & \multicolumn{3}{|c|}{$\begin{array}{c}\text { HX95 } \\
\text { Mean (Q1-Q3) }\end{array}$} & \multicolumn{3}{|c|}{$\begin{array}{c}\text { HX08 } \\
\text { Mean (Q1-Q3) }\end{array}$} & \multicolumn{3}{|c|}{$\begin{array}{c}\text { NoHX } \\
\text { Mean (Q1-Q3) }\end{array}$} \\
\hline & Females & Males & Total & Females & Males & Total & Females & Males & Total & Females & Males & Total \\
\hline $\begin{array}{l}\text { Number of persons in the } \\
\text { household, yourself included } \\
(n=1324)\end{array}$ & $2.9(2-4)$ & $2.5(1-3)$ & $2.8(2-4)$ & $2.9(2-4)$ & $2.6(2-4)$ & $2.8(2-4)$ & $3.0(2-4) a>, c>$ & $2.4(2-3)$ & $2.9(2-4)$ b > & $2.7(2-4) \mathbf{a}<, \mathbf{c}<$ & $2.4(1-3)$ & $2.6(2-4) \mathbf{b}<$ \\
\hline $\begin{array}{l}\text { Number of children below } \\
4 \text { years of age }(n=1259)\end{array}$ & $0.8(0-1)$ & $0.7(0-1)$ & $0.7(0-1)$ & $0.6(0-1)$ & $0.5(0-1)$ & $0.6(0-1)$ & $0.8(0-1) \mathbf{a}>$ & $0.5(0-1)$ & $0.7(0-1)$ & $0.7(0-1) a<$ & $0.6(0-1)$ & $0.6(0-1)$ \\
\hline $\begin{array}{l}\text { Hours a day taking care of } \\
\text { children } 0-4 \text { years of age } \\
(n=1234)\end{array}$ & $4.9(0-8) \mathbf{a}<$ & $1.9(0-3)$ & $4.2(0-6)$ & $5.8(0-8)$ a> & $1.0(0-1.5)$ & $4.3(0-5)$ & $5.5(0-8)$ a $>$ & $1.5(0-2)$ & $4.4(0-6.3)$ & $5.1(0-6)$ a > & $2.0(0-3)$ & $3.6(0-5)$ \\
\hline $\begin{array}{l}\text { Hours a day cooking } \\
(n=1314)\end{array}$ & $1.2(1-1.3)$ & $1.2(1-1)$ & $1.2(1-1)$ & $1.3(1-2) \mathbf{c}>$ & $0.9(0.5-1)$ & $1.2(1-1)$ & $1.3(1-2) c>$ & $1.2(0.8-1)$ & $1.3(1-1.3) \mathbf{b}>$ & $1.3(1-1.5) c>$ & $1.0(0.5-1)$ & $1.1(1-1) \mathbf{b}<$ \\
\hline $\begin{array}{l}\text { Hours a day cleaning/ } \\
\text { making laundry }(n=1304)\end{array}$ & $1.3(1-1.6) c>$ & $0.8(0.3-1)$ & $1.2(1-1) \mathbf{b}>$ & $1.1(1-1) c>$ & $0.7(0.4-1)$ & $1.0(1-1)$ & $1.3(1-2) a>, c>$ & $0.7(0.4-1)$ & $1.2(1-1) \mathbf{b}>$ & $1.1(1-1) \mathbf{a}<, \mathrm{c}>$ & $0.7(0.2-1)$ & $0.9(0,5-1) b<$ \\
\hline $\begin{array}{l}\text { Number of times a day } \\
\text { washing hands at home } \\
(\mathrm{n}=1309)\end{array}$ & $7.8(4-10) c>$ & $3.8(2-5)$ & $6.8(3-10)$ & $6.3(5-8) \mathbf{a}<, \mathbf{c}>$ & $5.0(3-5.3)$ & $5.9(4-8) \mathbf{b}<$ & $9.3(5-10) a>, c>$ & $4.7(3-5)$ & $8.0(4-10)$ b> & $7.2(4-10) a<, c>$ & $4.4(3-5)$ & $5.9(3-7) \mathbf{b}<$ \\
\hline $\begin{array}{l}\text { Number of times a day } \\
\text { washing hands at work } \\
(n=1260)\end{array}$ & $8.3(4-10) c>$ & $5.2(2.5-4)$ & $7.4(3-10) \mathbf{b}>$ & $7.6(3.5-11) c>$ & $4.3(3-4)$ & $6.5(3-8)$ & $9.7(4-10) a>, c>$ & $6.6(3-10)$ a > & $8.7(3-10)$ b> & $7.5(3-10) \mathbf{a}>\mathbf{c}<<$ & $4.5(2-5) \mathbf{a}<$ & $6.0(3-6) \mathbf{b}<$ \\
\hline $\begin{array}{l}\text { Number of times a day } \\
\text { washing hands, at home } \\
\text { and at work }(n=1255)\end{array}$ & $14.9(9-17) c>$ & $9.0(5-11.5)$ & $13.3(7-16)$ & $14.0(9-19.5) c>$ & $9.3(6.8-10)$ & $12.4(8-16) \mathbf{b}<$ & $18.7(10-21.5) a>, c>$ & $11.3(6-15) a>$ & $16.5(8-20) \mathbf{b}<$ & $14.5(8-16) \mathbf{a}>\mathbf{c}<$ & $8.8(5-10)$ a > & $11.7(6-14) \mathbf{b}<$ \\
\hline $\begin{array}{l}\text { If smoking; number of } \\
\text { cigarettes a day }(n=112)\end{array}$ & $7.5(5.8 .7 .8)$ & $3.5(2-5)$ & $6.7(2.9 .7 .3) \mathbf{b}<$ & $8.1(5-11.8)$ & $1(1.0)$ & $7.7(4.5-10.5)$ & $10.9(6-15)$ a> & $15(1.0)$ & $11.1(7-15) \mathbf{b}>$ & $6.5(2-10) a<$ & $7.6(2-11.5)$ & $7.1(2-10) \mathbf{b}<$ \\
\hline $\begin{array}{l}\text { If using protective gloves } \\
\text { at work: hours a day } \\
\text { using them ( } n=398)\end{array}$ & $2.8(13-5)$ & $3.9(2-5.8)$ & $3.1(1.5-4.5)$ b > & $1.6(1-2)$ & $2.4(0.5-4.5)$ & $1.8(1-2.8) \mathbf{b}<$ & $2.8(1-3)$ & $3.2(1-5.5)$ & $2.9(1-3.3)$ & $2.3(1-3) c<$ & $3.8(1-6)$ & $3.1(1-4)$ \\
\hline $\begin{array}{l}\text { Number of working hours } \\
\text { at ordinary work }(n=1279)\end{array}$ & $38.3(35-40.5)$ a> & $41.7(40-44)$ & $39.2(38-42)$ b> & $35.5(32-40) c<$ & $44.7(40-50)$ & $38.5(36-45)$ & $34.1(30-40) \mathbf{a}<, \mathbf{c}<$ & $41.8(40-45)$ & $36.3(30-40) \mathbf{b}<$ & $36.7(32-40) a>, c<$ & $41.9(40-45)$ & $39.2(38-40) \mathbf{b}>$ \\
\hline $\begin{array}{l}\text { Number of working hours at } \\
\text { ordinary and additional } \\
\text { work }(n=107)\end{array}$ & $42.7(32-49)$ & $57.0(57.0)$ & 44.1 (33-51.8) & $33.5(29-38)$ & $49.5(45-54.5)$ & $44.2(35.8,51.5)$ & $37.7(29.3,47.3)$ & $49.5(39-59)$ & $40.7(30.5,51.8)$ & $44.3(38.5,49.5) c<$ & $50.6(44-55)$ & $47.9(41-53)$ \\
\hline $\begin{array}{l}\text { Hours a week gardening } \\
(n=1270)\end{array}$ & $2.1(0-3)$ & $1.9(0-3.5)$ & $2.1(0-3)$ & $3.5(0-3)$ & $1.4(0-2)$ & $2.8(0-2.5)$ & $2.4(0-2.3)$ & $2.8(0-3)$ & $2.5(0-2.5)$ & $2.5(0-3)$ & $2.7(0-3)$ & $2.6(0-3)$ \\
\hline $\begin{array}{l}\text { Hours a week repairing } \\
\text { cars/engines }(n=1236)\end{array}$ & $0.2(0-0)<$ & $3.6(0-1)$ & $1.0(0-0)$ & $0.1(0-0) c<$ & $0.5(0-1)$ & $0.2(0-0)$ & $0.3(0-0) c<$ & $2.6(0-1)$ & $1.0(0-0)$ & $0.1(0-0) c<$ & $1.5(0-1)$ & $0.8(0-0)$ \\
\hline $\begin{array}{l}\text { Hours a week doing building } \\
\text { work, restoration }(n=1245)\end{array}$ & $1.7(0-2) c<$ & $4.2(0.6-5)$ & $2.3(0-2)$ & $1.1(0-1.5)$ & $3.1(0-3.5)$ & $1.7(0-2)$ & $2.8(0-1)$ & $3.3(0-2)$ & $2.9(0-1.5)$ & $2.4(0-1) c<$ & $5.1(0-4.8)$ & $3.8(0-2)$ \\
\hline $\begin{array}{l}\text { Hours a week doing sports } \\
(n=1251)\end{array}$ & $4.2(1-4)$ & $2.7(1-3.7)$ & $3.8(1-4)$ & $2.5(1-4)$ & $2.7(1-3.3)$ & $2.6(1-4)$ & $4.5(1-4.8)$ & $3.6(0.5-4)$ & $4.2(1-4)$ & $4.0(1-5)$ & $4.2(1-4)$ & $4.1(1-4)$ \\
\hline Hours a week doing & $4.7(2-5)$ & $3.4(0-6)$ & $4.4(2-5)$ & $3.2(0-4.8)$ & $1.8(0-3)$ & $2.7(0-4)$ & $4.0(0-4)$ & $5.0(0-4)$ & $4.3(0-4)$ & $3.4(0-4.5) c<$ & $5.2(0-5)$ & $4.3(0-5)$ \\
\hline
\end{tabular}

hobbies $(n=1035)$.

$4.7(2-5)$

$3.4(0-6)$

$4.4(2-5)$

$4.0(0-4)$

$5.0(0-4)$

Significant differences $(p<0.05)$ between groups, totals and/or genders are marked with bold letters. a: significant differences within females or within males in different groups, b: significant difference between
totals, c: significant difference between females and males in a group, < or $>$ : the group or the gender has significantly lower or significantly higher frequency than the compared group/groups. Kruskal-Wallis Test totals, c: significant difference between females and males in a group, < or >: the group or the gender has significantly lower or significantly higher frequency than the compared group/groups. Kruskal-Wallis Test and Mann-Whitney $U$ test 
NoHX group. The HX08 group smoked significantly more cigarettes than those in the HX9508 and NoHX groups ( $\mathrm{p}=0.023$ and 0.012 respectively).

Among the respondents 487/1323 (36.8\%) used moisturisers daily. The HX9508 group used moisturisers significantly more than the other groups, $71.1 \%$, followed by the HX08 group, $54.8 \%$, the HX95group, $45.7 \%$ and the NoHX group, 30.6\%, ( $\mathrm{p}<0.001)$. Among females $52.7 \%(n=746)$, used moisturisers every day; $79 \%$ in the HX9508 group, $61.3 \%$ in the HX08 group, $56.2 \%$ in the HX95 group and $47.4 \%$ in the NoHX group ( $<0.001)$. Among males $16.3 \%$ used moisturisers daily: $47.6 \%$ in the HX9508 group, $38.6 \%$ in the HX08 group, $22.7 \%$ in the HX95 group and $12.7 \%$ in the NoHX group $(\mathrm{p}<$ 0.001). Males with hand eczema used moisturisers as often as women without hand eczema.

\section{Factors predicting hand eczema}

The analysis of endogenous and exogenous factors was performed with multinominal logistic regression. The results are shown in Table 4. Having had childhood eczema was the most significant predictor for 1-year prevalence of hand eczema 2008 with odds ratios of 13.17 in the group HX9508 and 5.17 in the group HX08 compared to the group NoHX. The frequency of daily hand washing was significantly associated with the 1year prevalence of hand eczema only in the HX08 group. The daily usage of moisturisers was significantly associated with 1-year prevalence of hand eczema in the groups HX9508 and HX08. High odds ratios, 1.40, for predicting 1-year prevalence of hand eczema was found for female gender in the group HX9508. In the group HX08 the higher odds ratio for females was 1.19. However, none of these differences were significant.

\section{Discussion}

In this study comprising 1,516 young adults, the 1-year prevalence of hand eczema was more than $15 \%$. One third of these individuals also had 1-year prevalence at the baseline 1995. The 1-year prevalence, and not the point prevalence, was used in all calculations because it better reflects the persistency, the relapsing course and the seasonal variations of the disease $[2,19]$. The increase in the one-year prevalence between the two occasions is in accordance with previous large Swedish crosssectional studies with respect to the age groups [3-5,22].

The estimated incidence of hand eczema in our study was 11.6 cases per 1000 person-years, 14.3 among females and 5.2 among males. Our figures are in the upper amplitude compared to an earlier population based study from Sweden, which showed between 11.4 and 3.7 cases/1000 person-years among 20-29 year-old females and males, respectively [23]. One explanation could be that our study is prospective, and underreporting is to be expected in retrospective questionnaire studies [24]. Based on 7 European hand eczema studies performed among 16-77 years-olds, the median incidence rate of hand eczema was 9.6 cases/1000 person-years (range 4.6-11.4) among women and 4.0 cases/1000 personyears (range 1.4-7.4) among men [1], which is also slightly lower than our current findings, probably due to age-differences. To the best of our knowledge there are no comparable studies of the cumulative incidence in this age group. The cumulative incidence of hand eczema in our study across 13 years was $15.1 \%$ (18.6\% for females and $10.7 \%$ for males). This can be considered to be a high proportion [15]. When using a questionnaire for estimating the true occurrence of a disease it is important to know the sensitivity and specificity of the question used. The question on 1-year prevalence of hand eczema underestimates the occurrence. [25]. However, regarding childhood eczema the occurrence has been found to be overestimated especially if the true prevalence is low $[5,19]$. Based on prevalence as well as incidence, the occurrence of hand eczema is approximately twice as common among females compared to men, which is similar to other population-based studies $[1,26,27]$.

The advantage of a longitudinal cohort study compared with a cross-sectional study is that it enables the estimation of both cumulative incidence and incidence rate. Another advantage of performing a follow-up study is the possibility to compare the development of hand eczema over time in relation to different risk factors.

The four groups (HX9508, HX95, HX08 and NoHX) were used to investigate the relationship between childhood eczema and the incidence of hand eczema. The assumption was that a smaller proportion of individuals who had hand eczema in 2008 but not in 1995 reported childhood eczema. However, there were no significant differences between the three hand eczema groups concerning childhood eczema. Furthermore, it was found that a higher proportion of individuals who had hand eczema at both occasions reported childhood eczema.

Thus, in this cohort childhood eczema was the most important predicting factor regardless of the debut of hand eczema. In 2008, around $30 \%$ of our sample reported childhood eczema (females $36 \%$, males $20 \%$ ). In a large population-based Swedish study performed from 2002-2003, among 21-30 years-olds, childhood eczema was reported by $30.1 \%$ of females and $20.8 \%$ of males, $[4,28,29]$. The corresponding figures in the $31-40$ year-olds were $21.8 \%$ and $16.2 \%$ [30]. Thus, in our study, the prevalence of childhood eczema was higher. Similar to other studies, the relationship between having had hand eczema and reporting childhood eczema was highly significant [31]. The agreement in self-reports of childhood eczema at the two occasions was high. This high reliability over time in 
Table 4 Endogenous and exogenous factors associated with hand eczema analysed with logistic multinominal regression method, Group NoHX: never having had hand eczema, Group HX9508: having hand eczema 1995 as well as 2008, Group HX95: having had hand eczema only 1995 and Group HX08: having hand eczema only 2008

\begin{tabular}{|c|c|c|c|c|c|c|}
\hline \multirow[t]{2}{*}{ Group } & \multicolumn{2}{|c|}{ Group HX9508 vs Group NoHX (N = 852) } & \multicolumn{2}{|c|}{ Group HX95 vs Group NoHX (N = 836) } & \multicolumn{2}{|c|}{ Group HX08 vs Group NoHX (N = 895} \\
\hline & Odds-ratio & $\begin{array}{l}95 \% \mathrm{Cl} \text { for OR } \\
\text { (p-value) }\end{array}$ & Odds-ratio & $\begin{array}{c}95 \% \mathrm{Cl} \text { for OR } \\
\text { (p-value) }\end{array}$ & Odds-ratio & $\begin{array}{l}95 \% \mathrm{Cl} \text { for OR } \\
\text { (p-value) }\end{array}$ \\
\hline Having had childhood eczema & 13.17 & $6.74-25.72(<0.001)$ & 4.12 & $2.31-7.33(<0.001)$ & 5.17 & $3.33-8.03(<0.001)$ \\
\hline Having had asthma & 1.89 & $0.99-3.62(0.54)$ & 0.81 & $0.34-1.89(0.619)$ & 1.12 & $0.64-1.94(0.699)$ \\
\hline Having had rhino-conjunctivitis & 1.64 & $0.86-3.10(0.132)$ & 0.98 & $0.53-1.81(0.945)$ & 1.51 & $0.95-2.40(0.084)$ \\
\hline Female gender & 1.40 & $0.71-2.75(0.334)$ & 1.42 & $0.73-2.79(0.304)$ & 1.19 & $0.72-1.97(0.500)$ \\
\hline Number of times a day washing hands, at home and at work & 0.99 & $0.97-1.02(0.696)$ & 1.00 & $0.97-1.03(0.858)$ & 1.02 & $1.01-1.04(0.038)$ \\
\hline Usage of moisturisers: daily vs less than daily & 5.17 & $2.82-9.51(<0.001)$ & 1.49 & $0.81-2.73(0.199)$ & 2.11 & $1.34-3.30(0.001)$ \\
\hline Cooking:hours a day & 1.00 & $0.69-1.43(0.987)$ & 1.00 & $0.66-1.51(0.997)$ & 1.10 & $0.87-1.37(0.433)$ \\
\hline Washing and cleaning: hours a day & 1.19 & $0.81-1.77(0.377)$ & 0.81 & $0.48-1.39(0.446)$ & 1.23 & $0.94-1.60(0.126)$ \\
\hline Taking care of children $<4$ years old: hours a day & 1.01 & $0.97-1.06(0.616)$ & 1.02 & $0.98-1.07(0.321)$ & 0.99 & $0.96-1.03(0.707)$ \\
\hline
\end{tabular}

Odds-ratios (OR) in predicting 1-year prevalence of hand eczema 2008 compared to the group NoHX, group HX9508 compared to group NoHX and group HX08 compared to group NoHX . Confidence intervals (Cl), $95 \%$, and $\mathrm{p}$-values are given for all variables. Significant $\mathbf{O R}$, $\mathbf{C l}$ and $\mathbf{p}$-values are in bold text. 
this age-group can be useful to know when hand eczema is diagnosed. However, the lower rate of reported childhood eczema in 2008 can be explained by recall bias as was found in a study comprising respondents aged 31 to 42 years [32]. For the individuals who reported only rhino-conjunctivitis, there was no significant association with one-year prevalence of hand eczema. Also, there was no association with asthma only, but there were very few respondents. Thus in our study no additional information concerning risk for hand eczema was obtained by asking about asthma or rhino-conjunctivitis. These results are in accordance with Meding et al. who showed that asthma and rhino-conjuntivitis in adults were only associated with hand eczema at an age below 30 years [23]; in another study, including adolescents, a marginally significant association with inhalant allergy was found [33].

Analyses of exogenous factors showed that the individuals with hand eczema only in 2008, reported a significantly higher frequency of hand washing compared to the individuals without hand eczema.

Females with hand eczema spent significantly more time doing household activities than men with hand eczema (Table 3). Hand washing was more frequent among females with hand eczema than females without hand eczema as well as compared with men with hand eczema. In the multinominal regression analyses hand washing in the group HX08 was the only significant exogenous risk factor associated with hand eczema. In the majority of hand eczema studies hand washing is found to be the most significant risk factor for developing hand eczema [34]. In our cohort, other exogenous risk factors such as cooking, washing and cleaning and taking care of young children did not have any significant association with hand eczema. Furthermore, female gender was not a significant risk factor. However, it is well known that females have hand eczema more often than men. This can be explained by the high exposure to water and other skin irritants. Experimental as well as epidemiological studies [14,35] have demonstrated that female skin is not more sensitive to irritants than male skin [35] which is in line with our findings.

An interesting finding was the high odds-ratio in daily use of moisturisers in the two groups with current 1year prevalence of hand eczema (HX9508 and HX08). This pattern was not seen in the group having had hand eczema in 1995 (HX95).

When self-administrated questionnaires are used, it is important for the results to be adjusted based on sensitivity and specificity of validated questions. This is especially important in diseases that are common and affect the general health and well-being of individuals, such as hand eczema. The development of specific instruments like questionnaires implicates problems. In this case the questions regarding childhood and hand eczema were not validated in 1995 but 2,535 of the 2,572 pupils
(98.6\%) were clinically examined, and the sensitivity of $73 \%$ and the specificity of $99 \%$ were found [15]. The question regarding the 1-year prevalence of hand eczema, which was used in the present study and in the first study, was previously validated [19]. Thus, the true one-year prevalence of hand eczema can be estimated from our data and is $20.6 \%$ for all; $26.8 \%$ among females and $12.5 \%$ among males.

The answers to the open questions on occupation as well as work tasks gave no further information regarding risk factors for developing or maintaining hand eczema. This circumstance seems to be a common problem in questionnaire studies [3]. In a study regarding occupational exposure to water as a risk factor for hand eczema, it was found that the title of an occupation gave misclassified results; exposure time and frequency of water use were more appropriate measures [36]. For result validity, it is important to have high response rates in general population studies [37-39]. The response rate in this study was almost two thirds of the individuals who received a questionnaire in the mail. Females were significantly more willing to participate than the males. There were, however, no significant differences within the female or the male groups regarding having had 1year prevalence of hand eczema at the two occasions. The response rate was similar to the annual national public health questionnaire performed by Swedish $\mathrm{Na}$ tional Institute of Public Health [40].

\section{Conclusions}

This study demonstrated that incidence of hand eczema in early adulthood tends to be associated with factors in everyday life such as frequent hand-washing. Regarding childhood eczema, the odds ratio for having hand eczema was twice as high in the HX9508 group compared to the group HX08, indicating a high vulnerability in this group. Furthermore, early onset of hand eczema seemed to be related to endogenous risk factors such as a history of childhood eczema. The higher frequency of hand eczema among women depended on exogenous factors.

\section{Additional file}

Additional file 1: Questions from the questionnaire 2008.

Competing interests

The authors declare that they have no competing interests.

\section{Authors' contributions}

The authors together designed the study, analysed the data and wrote the manuscript. All authors read and approved the final manuscript.

\section{Acknowledgments}

This study was supported by grants from the Swedish Asthma and Allergy Research Foundation and the Finsen-Welander Foundation. We will also 
express our gratitude to Steven Schmidt for valuable comments and for revising the English text

\section{Author details}

'Department of Health Sciences, Lund University, Box 157, 22100 Lund, Sweden. ${ }^{2}$ Department of Occupational and Environmental Dermatology, Lund University, Malmö, Sweden. ${ }^{3}$ Department of Occupational and Environmental Dermatology, Malmö University Hospital, Malmö, Sweden. ${ }^{4}$ Department of Dermatology, Lund University, Malmö, Sweden. ${ }^{5}$ Department of Dermatology, Malmö University Hospital, Malmö, Sweden.

Received: 8 January 2013 Accepted: 22 October 2013

Published: 29 October 2013

\section{References}

1. Thyssen JP, Johansen JD, Linneberg A, Menné T: The epidemiology of hand eczema in the general population - prevalence and main findings. Contact Dermatitis 2010, 62:75-87.

2. Meding B: Epidemiology of hand eczema in an industrial city. Acta Derm Venereol 1990, 153(Suppl):1-43.

3. Montnemery P, Nihlen U, Lofdahl CG, Nyberg P, Svensson A: Prevalence of hand eczema in an adult Swedish population and the relationship to risk occupation and smoking. Acta Derm Venereol 2005, 85:429-432.

4. Meding B, Jarvholm B: Hand eczema in Swedish adults - changes in prevalence between 1983 and 1996. J Invest Dermatol 2002, 118:719-723.

5. Stenberg B, Meding B, Svensson A: Dermatology in public health - a model for surveillance of common skin diseases. Scandinavian J Public Health 2010, 38:368-374.

6. Bingefors K, Lindberg M, Isacson D: Quality of life, use of topical medications and socio-economic data in hand eczema: a Swedish nationwide survey. Acta Derm Venereol 2011, 91:452-458.

7. Flyvholm M, Bach B, Rose M, Frydendall Jepsen K: Self-reported hand eczema in a hospital population. Contact Dermatitis 2007, 57:110-115.

8. Van der Meer EW, Boot CR, Jungbauer FH, van der Klink JJ, Rustemeyer T, Coenraads PJ, van der Gulden JW, Anema JR: Hands4U: a multifaceted strategy to implement guideline-based recommendations to prevent hand eczema in health care workers: design of a randomised control trial and (cost) effectiveness evaluation. BMC Public Health 2011, 11:669.

9. Augustin M: Versorgungsforschung in der Dermatologie. Hautarzt 2011, 62:168-169.

10. Meding B, Wrangsjö K, Järvholm B: Fifteen-year follow-up of hand eczema: persistence and consequences. Br J Dermatol 2005, 152:975-980.

11. Moberg C, Alderling M, Meding B: Hand eczema and quality of life: a population-based study. Br J Dermatol 2009, 161:397-403.

12. Dickel H, Kuss O, Schmidt A, Kretz J, Diepgen TL: Importance of irritant contact dermatitis in occupational skin disease. Am J Clin Dermatol 2002, 3:283-289.

13. Nielsen NH, Linneberg A, Menne T, Madsen F, Frolund L, Dirksen A, Jorgensen T: The association between contact allergy and hand eczema in 2 cross-sectional surveys 8 years apart. The Copenhagen allergy study. Contact Dermatitis 2002, 47:71-77.

14. Bryld LE, Hindsberger C, Kyvik KO, Agner T, Menne T: Risk factors influencing the development of hand eczema in a population-based twin sample. Br J Dermatol 2003, 149:1214-1220.

15. Yngveson M, Svensson A, Isacsson A: Evaluation of a selfreported questionnaire on hand dermatosis in secondary school children. Acta Derm Venereol 1997, 77:455-457.

16. Yngveson M, Svensson A, Isacsson A: Prevalence of self-reported hand dermatosis in upper secondary school pupils. Acta Derm Venereol 1998, 78:371-4.

17. Susitaival P, Kanerva L, Hannuksela M, Jolanki R, Estlander T: Touhilampi Questionnaire for Epidemiological Studies of Contact Dermatitis and Atopy, People and Work. Research Report 10. Helsinki: Finnish Institute of Occupational Health; 1996.

18. Susitaival P, Flyvholm MA, Meding B, Kanerva L, Lindberg M, Svensson A, Olufsson JH: Nordic occupational skin questionnaire (NOSQ-2002): a new tool for surveying occupational skin diseases and exposure. Contact Dermatitis 2003, 49:70-76.

19. Meding B, Barregård L: Validity of self-reports of hand eczema. Contact Dermatitis 2001, 45:99-103.
20. Anveden I, Lidén C, Alderling M, Meding B: Self-reported skin exposure - validation of questions by observation. Contact Dermatitis 2006, 55:186-91.

21. Ahlbom A, Norell S: Introduction to Modern Epidemiology. Chestnut Hill: Epidemiology Resources Inc.; 1990:25-6.

22. Meding B, Lidén C, Berglind N: Self-diagnosed dermatitis in adults. Results from a population survey in Stockholm. Contact Dermatitis 2001, 45:341-345.

23. Meding B, Järvholm B: Incidence of hand eczema-a population-based retrospective study. J Invest Dermatol 2004, 122:873-877.

24. Bregnhøj A, Søsted H, Menné T, Johansen Duus J: Validation of self-reporting of hand eczema among Danish hairdressing apprentices. Contact Dermatitis 2011, 65:146-150.

25. Stenberg B, Lindberg M, Meding B, Svensson $\AA$ : Is the question "Have you had childhood eczema?" useful for assessing childhood atopic eczema in adult population surveys? Contact Dermatitis 2006, 54:334-337.

26. Yngveson M, Svensson A, Johannisson A, Isacsson A: Hand dermatosis in upper secondary school pupils: 2-year comparison and follow-up. Br J Dermatol 2000, 142:485-489.

27. Meding B: Differences between the sexes with regard to work-related skin disease. Contact Dermatitis 2000, 43:65.

28. Rystedt I: Hand eczema and long-term prognosis in atopic dermatitis. Acta Derm Venereol 1985, 117:1-59.

29. Nilsson E: Individual and environmental risk factors for hand eczema in hospital workers. Acta Derm Venereol 1986, 128(Suppl):1-63.

30. Röhrl K, Stenberg B: Lifestyle factors and hand eczema in a Swedish adolescent population. Contact Dermatitis 2010, 62:170-176.

31. Nyrén M, Lindberg M, Stenberg B, Svensson M, Svensson Å, Meding B: Influence of childhood atopic dermatitis on future worklife. Scand J Work Environ Health 2005, 31:474-478.

32. Moberg C, Meding B, Stenberg B, Svensson A, Lindberg M: Remembering childhood atopic dermatitis as an adult: factors that influence recollection. Br J Dermatol 2006, 155:557-560.

33. Mortz CG, Lauritsen JM, Bindslev-Jensen C, Andersen KE: Prevalence of atopic dermatitis, asthma, allergic rhinitis, and hand and contact dermatitis in adolescents. The Odense adolescence cohort study on atopic diseases and dermatitis. Br J Dermatol 2001, 144:523-532.

34. Anveden I, Wrangsjö K, Järvholm B, Meding B: Self-reported skin exposure - a population-based study. Contact Dermatitis 2006, 54:272-277.

35. Agner T: Noninvasive measuring methods for the investigation of irritant patch test reactions; a study of patients with hand eczema, atopic dermatitis and controls. Acta Derm Venereol 1992, 173(Suppl):1-26.

36. Anveden Berglind I, Alderling M, Järvholm B, Lidén C, Meding B: Occupational skin exposure to water: a population-based study. Br J Dermatol 2009, 160:616-621.

37. Edwards PJ, Roberts I, Clarke MJ, DiGuiseppi C, Wentz R, Kwan I, Cooper R, Felix LM, Pratap S: Methods to increase response to postal and electronic questionnaires (Review). Cochrane Database Syst Rev 2009(3):MR000008. doi:10.1002/14651858.MR000008.pub4

38. Data quality for the 2006 survey of labour and income dynamics (SLID). http://www.statcan.gc.ca/pub/75f0002m/2008005/section5-eng.htm.

39. Tolonen H, Helakorpi S, Talala K, Helasoja V, Martelin T, Prättäla R: 25-year trends and socio-demographic differences in response rates: Finnish adult health behaviour survey. Eur J Epidemiol 2006, 21:409-415.

40. Swedish National Institute of Public Health: http://www.fhi.se/Documents/ Statistik-uppfoljning/Folkhalsoenkaten/vad_betyder_bortfallet100330.pdf.

\section{doi:10.1186/1471-5945-13-14}

Cite this article as: Johannisson et al:: Prevalence, incidence and predictive factors for hand eczema in young adults - a follow-up study. BMC Dermatology 2013 13:14. 